\title{
Geociências
}

\section{Diamante variedade carbonado na serra do Espinhaço (MG/BA) e sua enigmática gênese}

\author{
Mario Luiz de Sá C. Chaves \\ Professor do IGC/UFMG e Pesquisador do MHN/UFMG, Belo Horizonte-MG \\ E-mail:mchaves@igc.ufmg.br \\ Paulo Roberto Gomes Brandão \\ Professor da EEng/UFMG e Pesquisador do CNPq, Belo Horizonte-MG \\ E-mail:pbrandao@demin.ufmg.br
}

\section{Resumo}

Carbonado, uma variedade policristalina do diamante, tem sua gênese alvo de intensas controvérsias. A discussão das principais hipóteses propostas para a questão, em associação com o enquadramento geológico das sequências pré-cambrianas que portam o material na serra do Espinhaço, parece favorecer uma dessas hipóteses. $\mathrm{Na}$ mesma, os microcristais que compõem o carbonado se formariam ordinariamente no manto, seriam trazidos para a crosta junto com os diamantes monocristalinos encontrados nessas sequências e, em estágio posterior, se agregando num ambiente sedimentar rico em material radioativo.

Palavras-chave: diamante, carbonado, serra do Espinhaço.

\begin{abstract}
Carbonado, a polycrystalline diamond variety, has a very controversial genesis. The geologic setting of the carbonado-bearing precambrian sequences in the Serra do Espinhaço, and other aspects regarding the genesis, seem to favor one specific hypothesis: the mycrocrystals that make up the carbonado could have been formed by the "usual" way within the mantle and were brought up to the crust together with large diamond crystals found in the same sequences; in a later stage, the mycrocrystals formed aggregates in a radioactive-rich sedimentary environment.
\end{abstract}

Keywords: diamond, carbonado, Espinhaço range. 


\section{Introdução}

Depósitos diamantíferos secundários, contendo juntamente diamante (monocristalino) e sua variedade policristalina carbonado, são típicos da serra do Espinhaço em Minas Gerais (região de Itacambira-Grão Mogol) e Bahia (região da Chapada Diamantina). Tal associação, longe de ser fortuita, indica condições anômalas e especiais de gênese desses diamantes. Os principais modelos atualmente propostos para explicar a formação dos carbonados são conflitantes, baseando-se em dados teóricos e/ou laboratoriais, sem levar em conta o condicionamento geológico de suas regiões de ocorrência. Dessa maneira, através da discussão sobre tais modelos genéticos, em associação com o enquadramento geológico das seqüências sedimentares originais onde eles se depositaram (Supergrupo Espinhaço), pretende-se nesse artigo contribuir para a definição de qual deles poderia ser melhor aplicado ao problema em questão ${ }^{1}$.

\section{Contexto geológico}

A unidade litoestratigráfica principal que sustenta o espigão serrano do Espinhaço é o Supergrupo Espinhaço (Figura 1), definindo uma grande província diamantífera onde a mineralização se depositou junto com seqüências rudáceas das formações Sopa-Brumadinho (Espinhaço Meridional), Grão Mogol (Espinhaço Central) e Tombador (Chapada Diamantina). Embora tais seqüências não sejam exatamente crono-correlatas (ver discussões em Uhlein \& Chaves, 2001), é interessante ressaltar que todas elas situam-se em porções basais do Supergrupo Espinhaço nas respectivas regiões.

A deposição do Supergrupo Espinhaço ocorreu entre 1,75-1,30 Ga (Paleo/ Mesoproterozóico), em bacia do tipo rift ensiálico encaixada na borda leste (caso do Espinhaço Meridional/Central) ou internamente (caso da Chapada Diaman-

${ }^{1} \mathrm{O}$ tema é também objeto de trabalho de PósDoutoramento efetuado no CPGEM/Escola de Engenharia da UFMG, por M. L. Chaves. tina) ao núcleo arqueano definido pelo Cráton do São Francisco; dobramento e metamorfismo em fácies xistos verdes verificaram-se durante o Ciclo Brasiliano no Neoproterozóico (e.g. Dussin \& Dussin, 1995). Na Chapada Diamantina, encontram-se os mais importantes depósitos contendo carbonados de todo mundo, onde a relação diamante/carbonado varia em torno de $90 / 10$ podendo em alguns locais atingir até 50/50 (Leonardos, 1937). No Espinhaço Central mineiro, carbonados ocorrem na região de Itacambira-Grão Mogol, associados à mesma unidade. Karfunkel et al. (2001) mencionam também a provável existência de carbonado no Grupo Macaúbas (Neoproterozóico), porém, como parte dessa seqüência glaciogênica formou-se às custas de contribuições terrígenas do Supergrupo Espinhaço, considera-se pouco relevante discutir sua fonte na mesma.

\section{Caracterização mineralógica}

Carbonados são diagnosticados

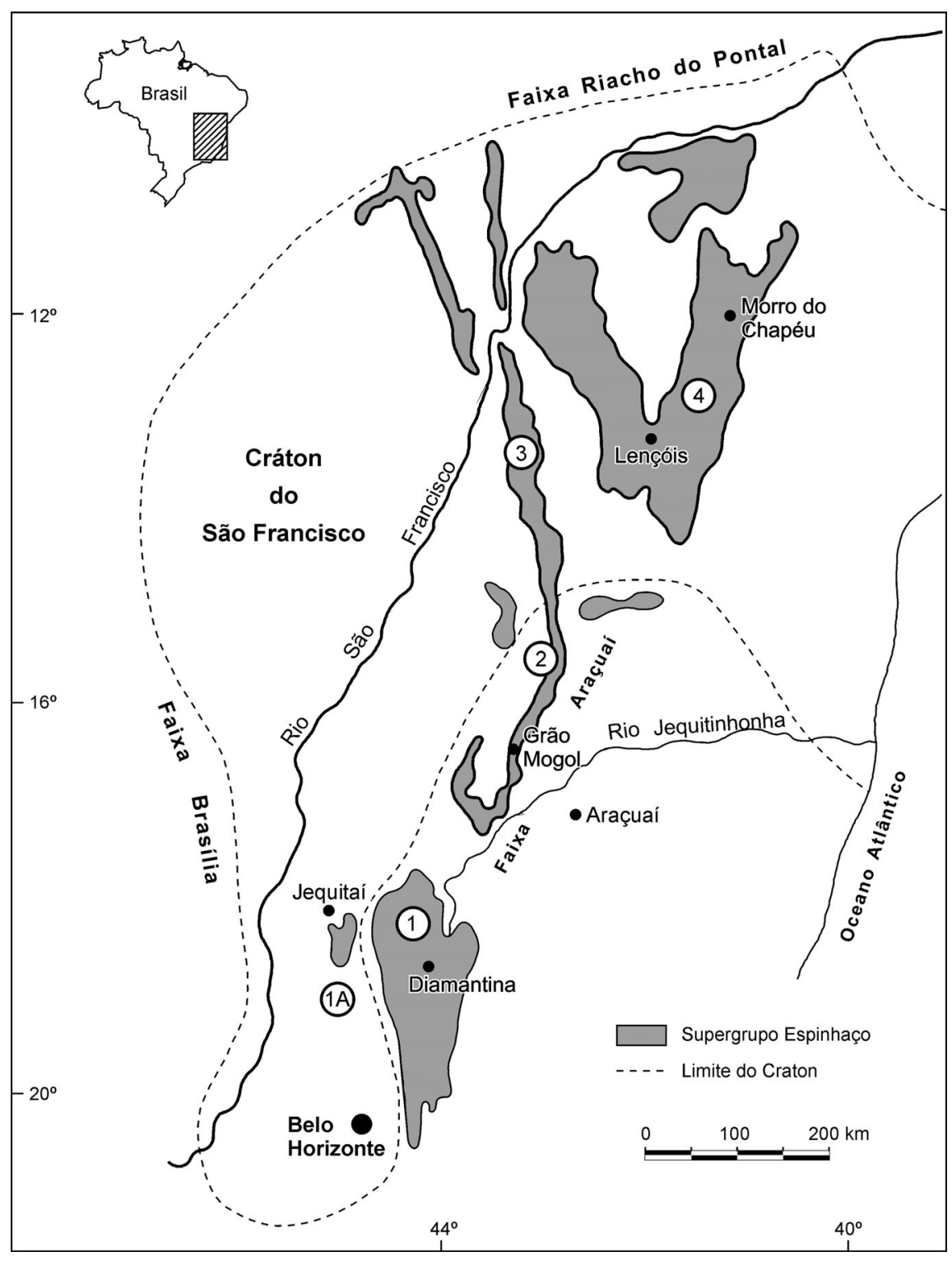

Figura 1 - Distribuição geográfica da serra do Espinhaço (em destaque) e da unidade estratigráfica que a sustenta, Supergrupo Espinhaço, na região centro-oriental brasileira. Domínios geográficos: 1 - Espinhaço Meridional; 2 - Espinhaço Central; 3 - Espinhaço Setentrional; 4 - Chapada Diamantina. 
Mario Luiz de Sá C. Chaves et al.

como diamantes desde a década de 1840 , quando começaram a ser lavrados nos depósitos aluvionares da Chapada Diamantina, Bahia (Leonardos, 1937). Nas décadas seguintes, o interesse econômico pelo material fez que, por diversas vezes, sua produção significasse $60-70 \%$ de toda a produção brasileira de diamantes. Em 1905, foi encontrado em Lençóis o maior de todos os carbonados, pesando 3.167ct. Designado de "Carbonado do Sérgio", ele é o maior diamante já encontrado no mundo, com peso superior em 61ct ao famoso "Cullinan" da África do Sul (3.106ct), de modo geral considerado o primeiro.

Carbonados ocorrem como indivíduos granulares, mais ou menos porosos e geralmente de coloração preta/cinzenta, amarronzada ou avermelhada, devido a uma fina película (pátina) que recobre os grãos (Figura 2). Constituem agregados policristalinos (indivíduos na faixa de 0,01-0,001mm, Orlov, 1973), mostrando dimensões totais inconstantes até $8 \mathrm{~cm}$ de diâmetro, como no "Carbonado do Sérgio”. A superfície de fratura de um carbonado revela, mesmo sob baixos aumentos, os cristalitos de diamante e os poros abundantes presentes (Figura 3). A densidade de amostras da Chapada Diamantina/Rio Macaúbas varia entre 3,10-3,40, inferior à do diamante monocristalino cujo valor (teórico) é 3,515. Essa densidade baixa é devida a sua porosidade maior (até $5 \%$ ), como também pela riqueza de inclusões "leves", tais como quartzo, ortoclásio e caulinita, junto a outras menos abundantes como rutilo, zircão, óxidos de ferro, fosfatos e ligas metálicas complexas.

Estudos descritivos sobre a morfologia do carbonado (e.g., Fettke \& Sturges, 1933, Kerr et al., 1948), assim como sobre sua estrutura e inclusões minerais, indicaram uma possível origem a partir de processos de sinterização, de modo semelhante aos materiais cerâmicos (Trueb \& Butterman, 1969, Trueb \& De Wys, 1969). Nesse modelo, carbonados seriam formados em altas temperaturas, quando impurezas adsorvidas se deslocariam para as bordas dos cristalitos, e recristalização parcial causaria a agregação destes. Entretanto nenhum processo geológico foi sugerido como causador do fenômeno.
Hall (1970) conseguiu experimentalmente a formação de possíveis "carbonados" sintéticos a partir de matéria grafitosa sob altas temperaturas. Robinson (1978) especulou que tais processos poderiam ocorrer em zonas de subducção pela in- filtração nas mesmas de material rico em carbono, hipótese essa que se tornou a primeira proposta genética de conotação geológica. Novamente, porém, não se especulou como os carbonados poderiam atingir depois os níveis crustais.

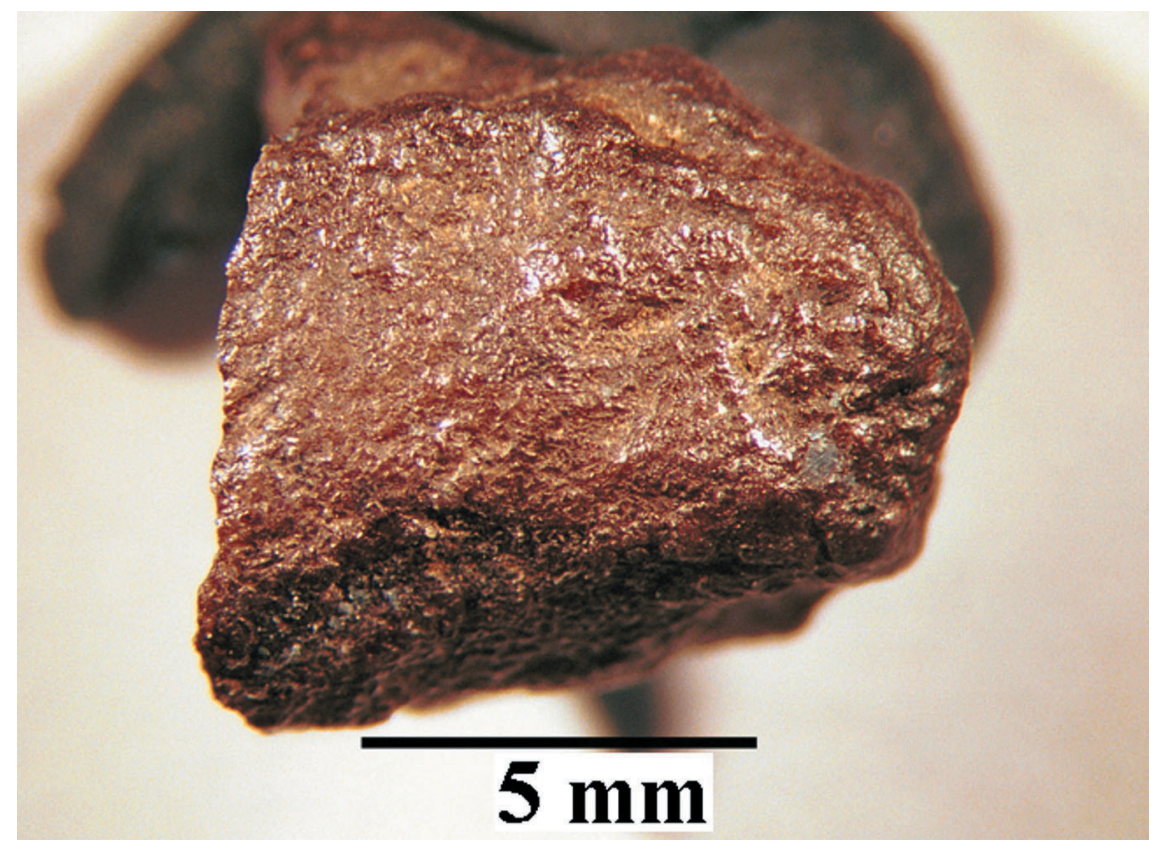

Figura 2 - Superfície original do carbonado, mostrando a pátina marrom-avermelhada escura e lustrosa (foto em microscópio estereoscópico).

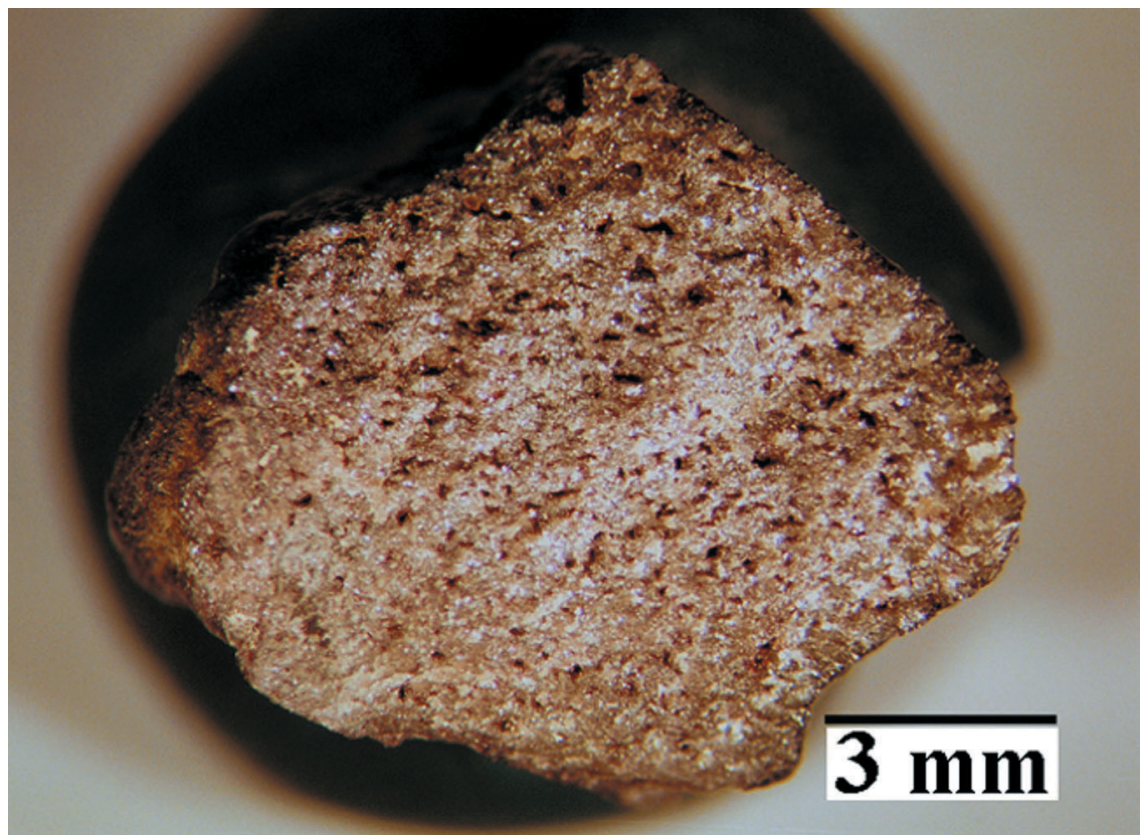

Figura 3 - Superfície de fratura de um carbonado, revelando os cristalitos de diamante (pequenos pontos brilhantes) e os poros (cor escura) relativamente grandes e abundantes; a pátina escura é visível na periferia do carbonado (foto em microscópio estereoscópico). 


\section{Modelamentos genéticos}

Além da "sugestão" precursora de Robinson (1978), quatro principais modelamentos mais elaborados quanto à gênese do carbonado são encontrados na literatura, detalhados a seguir.

\subsection{A hipótese de Smith e Dawson (1985)}

Segundo esses autores, carbonados se formariam pelo metamorfismo de impacto sobre rochas crustais contendo carbono orgânico ou grafita, pela queda de corpos extraterrestres durante o PréCambriano. Tal proposta baseou-se: (a) na presença de inclusões tipicamente crustais, além da ausência de fases indicadoras kimberlíticas; (b) no conteúdo de carbono "leve" ( $\left.\partial^{13} \mathrm{C} \cong-28\right)$, típico de rochas carbonosas crustais, enquanto diamantes kimberlíticos possuem taxas médias muito mais altas; (c) na grande probabilidade de terem ocorrido tais impactos sobre tais rochas carbonosas, baseando-se na observação de crateras na lua e planetas próximos; (d) na presença de diamante e lonsdaleíta nas crateras de impacto de Ries (Alemanha) e Popigai (Sibéria, Rússia). Polkanov et al. (1973, in Kaminsky, 1991) sugeriram que os agregados diamante-lonsdaleíta de aluviões da Ucrânia poderiam resultar de estruturas semelhantes.

Smith e Dawson (1985), no entanto, desconsideraram o fato de que carbonados estão sempre associados a di- amantes monocristalinos nos depósitos de pláceres (ou paleopláceres), como na serra do Espinhaço e na República Centro-Africana (CAR), omitindo o fato extremamente improvável de ocorrerem duas fontes distintas que supririam tais depósitos com diamantes e carbonados, em locais distantes entre si. Também foi mal esclarecido o fato de que, pelo bombardeio meteorítico pressuposto, enormes massas de quartzo teriam se transformado nos polimorfos coesita e stishovita, fases não encontradas nos pláceres em questão ou como inclusões nos carbonados.

\subsection{A hipótese de Kaminsky (1991)}

Estudos desse pesquisador russo levaram a uma considerável evolução sobre os processos de formação dos carbonados. De início, foi reconhecida a existência de dois tipos essencialmente distintos em termos de composição, propriedades e modo de formação: (i) carbonado comum, designado "Brazilian type" e (ii) "yakutita", uma nova variedade (Tabela 1). Na variedade yakutita, cuja composição química incluiria o polimorfo lonsdaleíta, estariam os agregados conhecidos em aluviões da Yakutia (Rússia). Esse material já havia sido descrito como "diamante hexagonal" (Bundy e Kasper, 1967) e "carbonado com lonsdaleíta" (Orlov \& Kaminsky, 1981), cuja gênese se daria pelo impacto de meteoritos sobre rochas crustais (Hanneman et al. 1967 - as três últimas citações em Kaminsky, 1991). Nessa ca- tegoria, também estariam os agregados encontrados em pláceres da Ucrânia.

Dessa maneira, Kaminsky (1991) argüiu contrariamente as idéias de Smith e Dawson (1985) sobre uma origem extraterrestre para a questão, assim como as de Hall (1970) e Robinson (1978), considerando que os carbonados sintéticos são diferentes dos seus congêneres naturais, desde o tamanho dos cristalitos (muito maiores nos sintéticos) até as características dos deslocamentos estruturais. Nos carbonados naturais, verifica-se uma alta densidade de deslocamentos, sendo tais feições orientadas irregularmente e nunca mostrando poligonalização (ao contrário dos sintéticos). Como essas últimas características são típicas de altas temperaturas, e carbonados não as apresentam, foi especulada uma possível influência de radioatividade para causar a agregação "fria" dos cristalitos.

Tendo como base pesquisas sobre películas de diamantes ultrafinas, a energia de superfície dos cristais recém-formados é um potencial termodinâmico independente e de direção oposta em relação ao potencial químico. Assim, quando o tamanho dos cristalitos é pequeno $(\mathrm{r}>100 \mathrm{~nm})$, o diagrama de equilíbrio grafita-diamante não difere do "tradicionalmente" conhecido. Entretanto, quando esse tamanho é muito mais reduzido $(\mathrm{r}<10 \mathrm{~nm})$, a superfície de equilíbrio de fases declina notavelmente para o domínio de baixa pressão. A agregação dos cristalitos no carbonado sob baixas pressões foi ainda apoiada no estudo de Breger (1964, in Kaminsky, 1991), que en-

Tabela 1 - Principais aspectos comparativos entre as variedades de diamante carbonado e yakutita (modificado de Kaminsky, 1991).

\begin{tabular}{l|l|l}
\multicolumn{1}{c|}{ Propriedades dos cristalitos } & \multicolumn{1}{c}{ Carbonado } & \multicolumn{1}{c}{ Yakutita } \\
\hline Forma & Irregular, isométrica & Hexagonal achatado \\
\hline Peso médio, em quilates (ct) & $1-40 \mathrm{ct}(<3167 \mathrm{ct})$ & $0,01-0,2 \mathrm{ct}(<2,2 \mathrm{ct})$ \\
\hline Tamanho dos cristalitos & $0,5-80 \mu \mathrm{m}$ (usualmente 10-40) & $0,1-1 \mu \mathrm{m}$ \\
\hline Estrutura & Ausente & Presente \\
\hline Fases do carbono, que não diamante & Não ocorrem & Lonsdaleíta $(<50 \%)$ \\
\hline Composição isotópica de carbono $\delta{ }^{13} \mathrm{C}$ & $-23,2$ a $-30,6 \%$ & $-9,9$ a $-20,1 \%$ \\
\hline \hline
\end{tabular}


controu "diamond-like clusters" em rochas uraníferas do Colorado (EUA), explicando tal fenômeno devido à radioatividade do meio.

\subsection{A hipótese de Ozima et al. (1991) e Kagi et al. $(1991,1994)$}

Após Kaminsky (1991) ter especulado que carbonados poderiam se formar na crosta, a partir de carvão exposto a U-Th, sem a existência de altas temperaturas e/ou pressões, Ozima et al. (1991) identificaram produtos de fissão espontânea nas composições isotópicas de gases nobres contidos nesses materiais. De modo semelhante, Kagi et al. (1991), ao observarem carbonados através de fotoluminescência induzida a laser, encontraram marcas de bombardeio por exposição à radioatividade; entretanto a conexão com rochas carbonosas, proposta por Kaminsky, foi considerada mera sugestão.

Novos estudos sobre carbonados da RCA levaram Kagi et al. (1994) a uma proposta genética complexa, onde a radioatividade teria um importante papel na agregação dos cristalitos de diamante, os quais, porém, teriam uma origem "ordinária" no manto. Da mesma forma que nos outros modelos, no entanto, esses autores não especificaram quais os possíveis mecanismos geológicos de geração dos microcristais de diamantes, nem seus modos de emplacement ou ambientes de agregação na crosta. Em síntese, propôs-se que os cristalitos se formaram no manto, com base na forma de ocorrência do nitrogênio contido nos cristalitos formando pequenas lamelas (platelets) por recozimento, comportamento típico de uma gênese mantélica. Posteriormente, na crosta, os microcristais seriam expostos a partículas-a emitidas por U/Th sob temperaturas e pressões moderadas. Tal processo resultaria na formação dos centros de cor bombardeados pela radiação e na "supercolagem" dos microcristais. Finalmente, esses sofreriam corrosão por fluidos hidrotermais, que ocasionariam também a dissolução do U e parte dos elementos terras-raras contidos nas inclusões, além da incorporação de minerais de origem crustal.

\subsection{A hipótese de Haggerty (1995)}

Nesse modelo, aspectos interessantes do carbonado foram ressaltados, como a cor geral cinza-escura com tonalidades variáveis até preta-azeviche, marrom e avermelhada; a pátina externa implicando fusão e rápido resfriamento; a porosidade alta, embora a permeabilidade seja extremamente baixa; e a ausência de inclusões "verdadeiras", pois as inclusões conhecidas representam materiais infiltrados entre os grãos. A partir desses dados e pelo fato de sua distribuição ser muito restrita, porém aparecendo em quantidades apreciáveis no Brasil e na República Centro-Africana, Haggerty (1995) especulou que algum mecanismo exótico deveria ser requerido para a síntese do material.

A hipótese procurou mostrar que um stress hidrodinâmico gerado acusticamente poderia ocorrer sob temperaturas $\left(>5000^{\circ} \mathrm{C}\right)$ e pressões (acima de 1 Mbar) superelevadas. Tais condições se dariam durante a cavitação momentânea (de micro- a picosegundo) de microbolhas em colapso e implosão, as quais excedem largamente as mínimas requeridas para a formação de diamantes. Embora a cavitação tivesse sido previamente sugerida para a cristalização do mineral em kimberlitos (Galimov, 1973), considerouse tal processo pouco plausível nessas rochas, pois a formação de bolhas é um fenômeno de baixa pressão de confinamento, estando em desacordo com a presença comum de inclusões de pressão alta a muito alta nos diamantes.

O material de "partida", proposto neste modelo, seria a água molecular tridimensional na forma de gelo (clatrato), de ocorrência natural nas margens continentais dos oceanos. Os clatratos constituem estruturas cristalinas porosas (verdadeiras "gaiolas"), onde gases estão aprisionados; seus tipos "I" e "II" são cúbicos, os últimos possuindo simetria estrutural do diamante, além de versatilidade para hospedar moléculas de gases de pequeno e grande diâmetros. Haggerty (1995) afirmou que o metano, comum nos clatratos naturais, seria o gás preferencial sugerido. Na presença de água, são conseguidas altas proporções $\mathrm{H}: \mathrm{C}$ causando protonação (i.e., hidrogênio) e a adesão requerida para a colagem do diamante, processo semelhante ao de deposição a vapor para síntese de filmes ultrafinos de diamantes sob baixas pressões e altas temperaturas no estado de plasma.

Assim, a cavitação acelerada balisticamente poderia justificar a porosidade, os gases nobres detectados, as pátinas de fusão e a própria colagem. A fonte sônica, desconhecida, teve algumas suposições: atividade sísmica intensa, explosões sônicas associadas a vulcanismo explosivo, choque e irradiação transmitidos pelo som devido ao impacto de meteorito ou cometa, etc. Haggerty (1995) finalizando, deixou a questão: a formação dos carbonados teria então ocorrido em evento único, arqueano, quando Brasil e República Centro-Africana seriam territórios contíguos? Assim, caso o processo for relacionado ao impacto de corpos extraterrestres, a cratera Chicxulub, do limite K-T na Península de Yucatan (México), poderia ser um ambiente ideal de formação (e procura) de carbonados.

\section{Discussão sobre - problema na serra do Espinhaço}

Os modelamentos genéticos previamente discutidos, com soluções complexas, díspares, e nenhuma delas apoiada em dados geológicos de campo, fazem crer que o problema da gênese dos carbonados ainda está longe de uma resposta final. Entretanto, a partir do conhecimento geológico sobre a região do Espinhaço, deve-se ressaltar que:

- Carbonados ocorrem na matriz de rochas metassedimentares rudáceas, juntamente com diamantes monocristalinos, nas regiões da Chapada Diamantina (BA) e do Espinhaço Central (MG), em seqüências proterozóicas designadas de Formação Tombador e Formação Grão Mogol, respectivamente. No Espinhaço Meridional (também em MG), nunca foi constatada a 
presença de carbonados nos conglomerados diamantíferos (Formação Sopa-Brumadinho). É interessante observar que as duas unidades portadoras de carbonados são crono-correlatas e situam-se sobre a Formação Sopa-Brumadinho (Chaves et al., 1999, Uhlein \& Chaves, 2001). Assim, parece que a época de maior aporte de carbonados é algo posterior à fase rift inicial, datada entre 1,75-1,70 Ga (e.g. Dussin \& Dussin, 1995, Uhlein \& Chaves, 2001), quando houve o suprimento dos sedimentos formadores da base do Supergrupo Espinhaço a partir de uma área-fonte a oeste, no Cráton do São Francisco.

- Considera-se improvável que, na áreafonte dos sedimentos que alimentaram a bacia Espinhaço, houvesse, ao mesmo tempo, intrusões ultrabásicas kimberlíticas/lamproíticas e o choque cataclísmico de algum bólido espacial com a Terra (como proposto nas hipóteses de Smith \& Dawson, 1985, e de Haggerty, 1995), para gerarem quase simultaneamente diamantes monocristalinos e carbonados. Dessa maneira, essas duas hipóteses parecem estar bastante prejudicadas frente ao contexto geológico verificado no Espinhaço. Além disso, Chaves (1997) considerou as populações de diamantes (monocristalinos) encontradas no Espinhaço Meridional/Central como muito semelhantes, sugerindo, assim, uma provável origem comum para ambas.

- De outro modo, a hipótese de Kaminsky (1991), aperfeiçoada com os estudos de Ozima et al. (1991) e Kagi et al. (1991, 1994), indicou que os carbonados se formaram em níveis provavelmente sedimentares ricos em $\mathrm{U} e$ Th, onde microdiamantes mantélicos teriam condições de se agregar em baixas temperatura e pressão. Nesse contexto, salienta-se que uma das características das populações de diamantes da serra do Espinhaço é a presença conspícua de cristais com "capa verde", cuja gênese é atribuída à radioatividade emanada a partir de minerais e/ou soluções ricas em $\mathrm{U}$ e $\mathrm{Th}$ (e.g. Vance et al. 1973, Chaves et al. 2001).
- Embora desconhecido, tal ambiente gerador da agregação dos microdiamantes em carbonados, responsável pela formação das capas verdes nos diamantes monocristalinos e cujas rochas já foram erodidas durante o próprio processo de evolução da bacia do Espinhaço, deve ter sido intracratônico, pós-emplacement das rochas fontes primárias, além de sin- a pósrifteamento gerador da bacia do Espinhaço. Esse ambiente sedimentar, aqui designado de "camada-X", foi provavelmente continental e de calmaria tectônica, recebendo a contribuição de rochas graníticas cratônicas, ricas em minerais radioativos.

\section{Conclusão}

Embora, na atualidade, a definição da gênese do diamante tenha atingido um adiantado grau de compreensão, a variedade policristalina carbonado ainda carece de conhecimento adequado. Muitos pesquisadores, em particular japoneses e russos, procuram o entendimento de tal mecanismo genético, visando a objetivos comerciais de produzir diamantes sintéticos a custos inferiores. No presente estudo, procurou-se demonstrar que o equacionamento de tal questão deve, de modo obrigatório, passar pela contextualização geológica, a qual foi sempre relegada a segundo plano, e que análises ainda mais sofisticadas que as atualmente disponíveis fazem-se necessárias para tal compreensão. Não obstante, acredita-se que, entre os modelos explicados, a hipótese de Kagi et al. (1994) parece a que mais está adequada ao conhecimento geológico disponível para os depósitos brasileiros. Nesse contexto, as capas verdes se formaram nos diamantes monocristalinos e os carbonados se agregaram conjuntamente, em um mesmo ambiente sedimentar aqui designado de "camada-X".

\section{Referências bibliográficas}

CHAVES, M.L.S.C. Geologia e mineralogia do diamante da serra do Espinhaço em Minas Gerais. São Paulo: Inst. Geociências-USP, 1997, 289p. (Tese de Doutorado).
CHAVES, M.L.S.C. et alii. Geologia da região diamantífera de Grão Mogol, Minas Gerais. Geocências, v.18, p.129-155, 1999.

CHAVES, M.L.S.C. et alii. Discussão sobre a natureza das cores verde e marrom (em capas ou verdadeiras) em diamantes do SE-Brasil. Rev. Bras. Geoc., v. 31, p.575-582, 2001.

DUSSIN, I.A., DUSSIN, T.M. Supergrupo Espinhaço: modelo de evolução geodinâmica. Geonomos, v.3, p.19-26, 1995 .

FETTKE, C.R., STURGES, F.C. Structure of carbonado or black diamond. Amer. Mineral., v. 18, p. $172-174,1933$

GALIMOV, E.M. Possibility of natural diamond synthesis under conditions of cavitation occurring in a fast moving magmatic melt. Nature, v. 243 , p. 389-391, 1973.

HAGGERTY, S.E. Carbonado, clathrate and cavitation: a model for the acoustic induction of diamond. In: INTERNAT. KIMBERLITE CONF., 6, 1995. Novosibirsk, Extended Abstracts... Novosibirsk, 1995, p. 217-219.

HALL, H.T. Sintered diamond, a synthetic carbonado. Science, v.169, p.868-869, 1970.

KAGI, H. et alii. Laser-induced luminescence from natural polycrystal diamond. Naturwissenschaften, v.78, p.355-358, 1991.

KAGI, H. et alii. Chemical properties of Central African carbonado and its genetic implications. Geoch. Cosmoch. Acta, v.58, p. 2629-2638, 1994.

KAMINSKY, F.V. Carbonado and yakutite: properties and possible genesis. In: INTERNAT. KIMBERLITE CONF., 5, 1991. Proceedings... Araxá, CPRM, Brasília, 1994, p.136-143.

KARFUNKEL, J. et alii. Diamonds from the Macaubas river basin (MG): characteristics and possible source. Rev. Bras. Geoc., v.31, p.445456, 2001.

KERR, P.F. et alii. Carbonado from Venezuela. Amer Mineral., v.33, p.251-255, 1948

LEONARDOS, O.H. Diamante e carbonado na Bahia. Avulso DNPM/SFPM, v.19, p.1-28, 1937.

ORLOV, Y. Mineralogy of the diamond. New York: John Wiley, 1973. 235p.

OZIMA, M. et alii. Constraints from noble-gas contents on the origin of carbonado diamonds. Nature, v.351, p.472-474, 1991.

The Ukraine. Dopovidi Na USSR, v.B11, p.989990, 1973.

ROBINSON, D.N. The characteristics of natural diamond and their interpretation. Minerals Sci. Eng., v.10, p.55-72, 1978.

$\mathrm{SANO}$, Y. et alii. Ion microprobe $\mathrm{Pb}-\mathrm{Pb}$ dating of carbonado, polycrystalline diamond. Prec. Res., v.113, p.155-168, 2002.

SMITH, J.V., DAWSON, J.B. Carbonado: diamond aggregates from early impacts of crustal rocks? Geology, v.13, p.342-343, 1985.

TRUEB, L.F., BUTTERMAN, W.C. Carbonado: a microstructural study. Amer. Mineral., v.54, p.412-425, 1969 .

TRUEB, L.F., DE WYS, E.C. Carbonado: natural polycrystalline diamond. Science, v.165, p.799802, 1969.

UHLEIN, A., CHAVES, M.L.S.C. O Supergrupo Espinhaço em Minas Gerais e Bahia: correlações estratigráficas, conglomerados diamantíferos e evolução geodinâmica. Rev. Bras. Geoc., v.31, p. 433-444, 2001.

VANCE, E.R. et alii. Possible origins of a-damage in diamonds from kimberlite and alluvial sources. Mineral. Mag., v.39, p.349-360, 1973.

Artigo recebido em 30/05/2003 e aprovado em $05 / 05 / 2004$. 